\title{
Prognostic role of matrix metalloproteinase 9 in early breast cancer
}

\author{
KATARINA KALAVSKA ${ }^{1,2^{*}}$, ZUZANA CIERNA $^{3,4^{*}}$, MARIAN KARABA $^{5,6}$, GABRIEL MINARIK $^{7}$, \\ JURAJ BENCA ${ }^{5,8}$, TATIANA SEDLACKOVA ${ }^{9}$, DENISA KOLEKOVA ${ }^{1}$, IVANA MRVOVA ${ }^{3,4}$, \\ DANIEL PINDAK $^{5,6}$, JOZEF MARDIAK ${ }^{10}$ and MICHAL MEGO ${ }^{1,10}$ \\ ${ }^{1}$ Translational Research Unit, Faculty of Medicine, Comenius University, 83310 Bratislava; \\ ${ }^{2}$ Department of Molecular Oncology, Cancer Research Institute, Biomedical Research Center of the
}

Slovak Academy of Sciences, 94505 Bratislava; ${ }^{3}$ Department of Pathology, Faculty of Medicine, Comenius University,

81108 Bratislava; ${ }^{4}$ Department of Pathology, Faculty Hospital, 91702 Trnava; ${ }^{5}$ Department of Oncosurgery,

National Cancer Institute, 83310 Bratislava; ${ }^{6}$ Department of Surgical Oncology, Slovak Medical University, 83303 Bratislava;

${ }^{7}$ Institute of Molecular Biomedicine, Faculty of Medicine, Comenius University, 81108 Bratislava;

${ }^{8}$ Department of Medicine, St. Elizabeth University, 81001 Bratislava; ${ }^{9}$ Geneton Ltd., 84104 Bratislava;

${ }^{10}$ Second Department of Oncology, Faculty of Medicine, Comenius University,

National Cancer Institute, 83310 Bratislava, Slovakia

Received June 9, 2020; Accepted October 20, 2020

DOI: 10.3892/ol.2020.12339

\begin{abstract}
MMP9 is involved in extracellular matrix degradation during various physiological and pathological conditions, including tumorigenesis. The present study aimed to assess the prognostic role of intratumoral MMP9 and to determine its association with circulating tumor cells (CTCs) in patients with early breast cancer. A total of 318 patients with primary breast cancer (PBC) were enrolled into the present study. Specimens were subjected to immunohistochemistry analysis, using the MMP9 monoclonal antibody. MMP9 expression was scored using a weighted histoscore (WH). The results demonstrated that the mean $\mathrm{WH} \pm \mathrm{SEM}$ for MMP9 expression was significantly higher in breast tumor cells compared with tumor associated stromas $(132.0 \pm 5.2$ vs. $50.8 \pm 3.7 ; \mathrm{P}<0.00001)$. Furthermore, a positive association was observed between MMP9 expression, the hormone positive status and proliferation index of analysed breast cancer tumour cells. Notably, the prognostic role of MMP9
\end{abstract}

Correspondence to: Professor Michal Mego, Second Department of Oncology, Faculty of Medicine, Comenius University, National Cancer Institute, Klenova 1, 83310 Bratislava, Slovakia

E-mail:misomego@gmail.com

*Contributed equally

Abbreviations: MMP9, matrix metalloproteinase 9; CTCs, circulating tumor cells; EMT, epithelial-to-mesenchymal transition; ER, estrogen receptor; $\mathrm{HR}$, hazard ratio; $\mathrm{PBC}$, primary breast cancer; $\mathrm{PR}$, progesterone receptor; RT-PCR, reverse transcription PCR; NA, non-applicable

Key words: matrix-metalloproteinase 9, early breast cancer, prognostic value, circulating tumor cells was not observed in tumor cells [hazard ratio $(\mathrm{HR})=0.96 ; 95 \%$ confidence interval (CI), 0.58-1.59; $\mathrm{P}=0.864]$ or tumor associated stroma $(\mathrm{HR}=1.29 ; 95 \% \mathrm{CI}, 0.60-2.78 ; \mathrm{P}=0.547)$. Subgroup analysis demonstrated that patients that were HR negative or triple negative, with low MMP9 expression in tumor cells and stroma had a significantly improved disease-free survival than patients with high MMP9 expression. Taken together, the results of the present study demonstrated that high MMP9 expression in PBC was associated with favorable tumor characteristics. However, the prognostic value of MMP9 was limited to only the HR negative and CTC epithelial-to-mesenchymal transition positive subgroups. Thus, analyzing MMP9 tumor expression may help identify patients with increased risk of disease recurrence in these subgroups.

\section{Introduction}

Breast cancer is the most common malignancy in women worldwide, whereby 2,088,849 new cases of invasive breast cancer and 626,679 mortalities were reported in $2018(1,2)$. Tumor invasion and metastasis affect $>90 \%$ of patients with breast cancer, and thus notably contribute to the high mortality rate (3-5). This metastatic disease remains incurable, and effective treatment for end-stage metastatic breast cancer are yet to be determined (6-8). The aggressiveness of a tumor is closely associated with its ability to evade natural barriers, to invade adjacent tissues and metastasize distant sites (9). The metastatic cascade is a multistep process where cancer cells escape from the primary tumor site to distant locations, where they can potentially establish new cancer colonies $(10,11)$. Under optimal conditions, epithelial cancer cells detach from the primary tumor site, penetrate and migrate via peripheral circulation, and invade secondary sites, where they ultimately undergo extravasation and populate distant organs $(11,12)$. 
Proteolytic degradation of the basement membrane and extracellular matrix (ECM) is considered a crucial aspect of metastatic growth, which enables low anchorage of neoplastic cells (13-17). Several cell-secreted proteolytic enzymes, including matrix metalloproteinases (MMPs) are implicated in the cleavage of ECM $(13,18,19)$. Matrix metalloproteinase 9 (MMP9) is a member of the gelatinase subfamily of MMPs and is secreted by a variety of cell types in an inactive form that undergoes activation upon cleavage by different types of extracellular proteases $(18,20)$. MMP9 activity is modulated via different biochemical molecules, including growth factors and cytokines $(19,21)$. Notably, MMP9 is actively involved in the degradation of type IV collagen, which is a crucial component of the basement membrane $(19,22)$. In addition, MMP9 facilitates the dissemination machinery, and is particularly involved in tumour invasion, tumour-induced angiogenesis, and immunomodulation of the tumour microenvironment, where it is implicated in the formation of so-called premetastatic niches $(23,24)$. Previous studies have focused on the association between high MMP9 expression and the number of distant metastases in patients with breast cancer (25-27), as well as poor prognosis $(28,29)$. It has been speculated that circulating tumor cells (CTCs), which are responsible for distant metastasis formation, use MMPs to form new metastatic sites $(19,30)$. In addition, a previous study demonstrated that elevated MMP1 expression is significantly associated with the presence of CTC_epithelial-to-mesenchymal transition (EMT) cells in the peripheral blood of patients with primary breast cancer (PBC), as well as with poor prognostic features of their primary tumors (31). The present study aimed to assess MMP9 expression in tumor cells as well as tumor associated stroma of patients with $\mathrm{PBC}$, and determine its association with the presence of CTCs in the peripheral blood of these patients and other clinicopathological characteristics. The prognostic value of MMP9 in patients with PBC was also assessed.

\section{Patients and methods}

Study patients. The present study (Protocol TRU-SK 002; Chair: Michal Mego) enrolled 318 patients with stages I-III PBC who underwent definitive surgery. The samples were collected from the National Cancer Institute (Bratislava, Slovakia) between March 2012 and February 2015. The paraphing embedded tumor tissue and CTCs status in peripheral blood were available for all patients included in the present study. Complete diagnostic evaluation was performed in all patients to exclude the presence of distant metastasis. Patients with concurrent malignancy in the last 5 years, other than non-melanoma skin cancer, were excluded from the present study. The clinicopathological data including age, tumor stage, histology, regional lymph node involvement, hormone receptor status and HER2 status were retrieved and tabulated from the patients' records after obtaining all the relevant ethical approvals.Breast cancer subtypes were identified by immunohistochemical staining (see below) and classified according to the ESMO Clinical Practice Guidelines for diagnosis, treatment and follow-up for early breast cancer (32).

The present study was reviewed and approved by the Institutional Review Board of the National Cancer Institute of Slovakia, Bratislava, Slovakia (TRUSK002, 20.6.2011).
Written informed consent was provided by all patients prior to the study start.

Tumor pathology. Pathological review was performed at the Department of Patholoxgy, Faculty of Medicine, Comenius University, (Bratislava, Slovakia) by an experienced pathologist (ZC).

Tumor samples and tissue microarray construction. Tumor specimens used in the present study were classified according to the 2019 World Health Organization classification (33). According to the tumor histology results, one or two representative areas containing the most representative part of the hematoxylin and eosin (H\&E) stained tumor tissues were observed under a light microscope, original magnification $\times 400$. The identified sections were matched to their corresponding wax blocks (donor blocks). The 3-mm diameter cores of the tumors were removed from the donor blocks using the multipurpose sampling tool HarrisUni-Core (Sigma-Aldrich; Merck KGaA) and inserted into the recipient master block. The recipient block was cut into $5-\mu$ m-thick sections, which were transferred onto coated slides.

Immunohistochemical (IHC) staining. Deparaffinized slides were rehydrated in phosphate buffered saline solution (10 mM, pH 7.2). Tissue epitopes were demasked using the automated water bath heating process in Dako PT Link (Dako; Agilent Technologies, Inc.) and the slides were incubated in $\mathrm{pH} 6.0$ citrate retrieval buffer at $98^{\circ} \mathrm{C}$ for $20 \mathrm{~min}$. The slides were subsequently incubated for $1 \mathrm{~h}$ at room temperature with primary mouse monoclonal antibody against MMP9 (Abcam; MMP9 (SB15c); cat. no. ab51203) diluted 1:200 in Dako REAL antibody diluent (Dako; Agilent Technologies, Inc.) and immunostained with anti-mouse/anti-rabbit immuno-peroxidase polymer (EnVision FLEX/HRP, Dako; Agilent Technologies, Inc.) for $30 \mathrm{~min}$ at room temperature, according to the manufacturer's instructions. The reaction was visualized using diaminobenzidine substrate-chromogen solution (Dako; Agilent Technologies, Inc.) for $5 \mathrm{~min}$, and the slides were counterstained with hematoxylin. The human clone tissue served as the positive control, and colon tissue subjected to the same procedure omitting the primary antibody was used as the negative control.

IHC evaluation. Tumor scores were blindly assessed by a pathologist (ZC). The results of the IHC analyzes were scored using a weighted histoscore (WH), assessing both the percentage of positive cells (PP) and the staining intensity (SI) of the cytoplasm as follows: The proportion of cells with nuclear staining was multiplied by the intensity of staining to provide a histoscore ranging from 0-300. The histoscore was calculated as follows: Score $=(0 \mathrm{x}$ percentage not stained $)+(1 \mathrm{x}$ percentage weakly stained $)+(2 x$ percentage moderately stained $)+$ (3x percentage strongly stained) (34). The mid-point of WH histoscore was used as the cut-off criterion similary as previosly $(35,36)$. MMP9 expression was stratified as low vs. high, according to the cut-off value of WH histoscore (150).

Detecting CTCs in peripheral blood. CTCs were identified via reverse transcription-quantitative (RT-q)PCR analysis. 

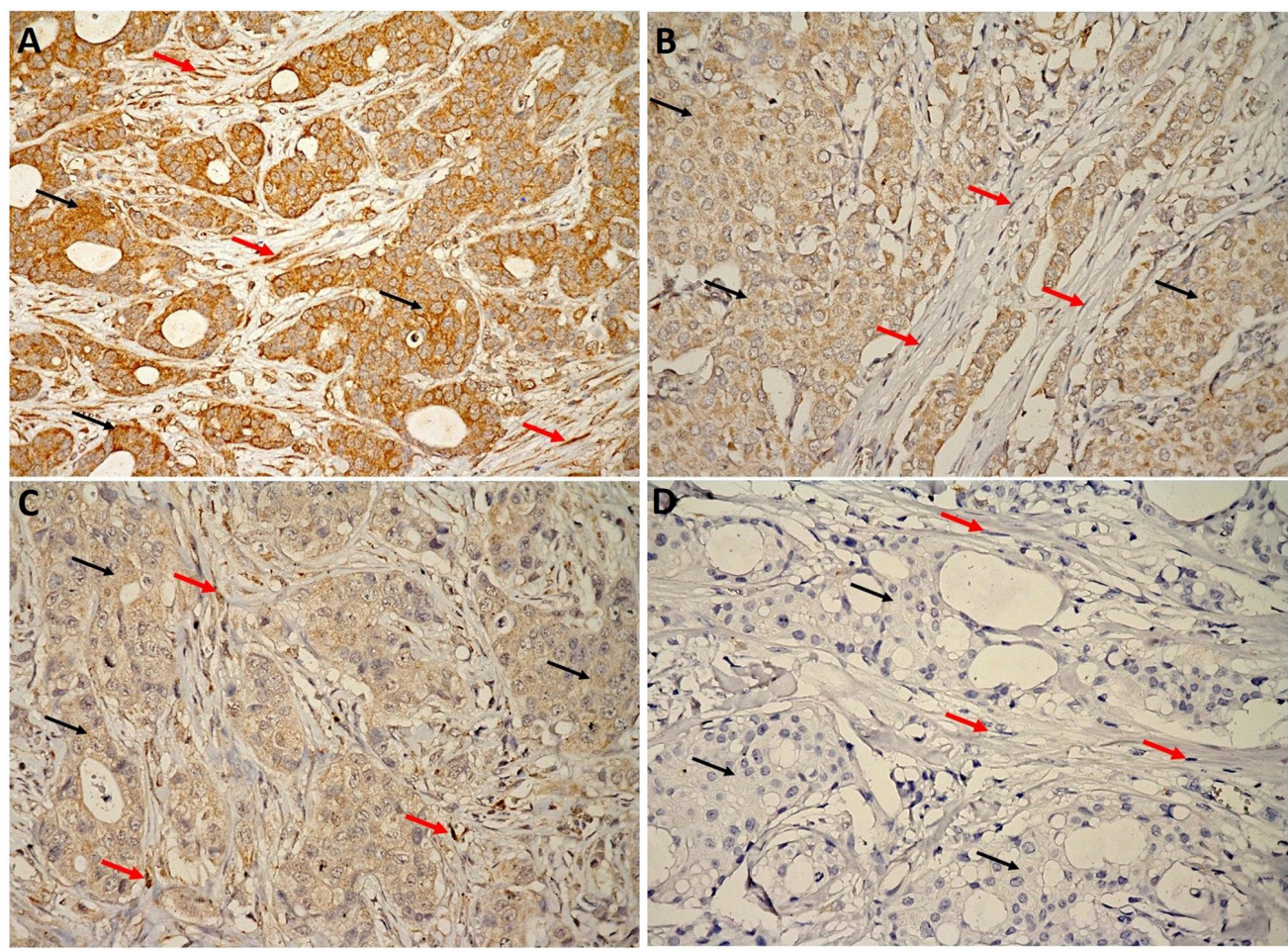

Figure 1. MMP9 expression in primary breast tumors. Immunohistochemical analysis was performed using anti-MMP9 monoclonal antibodies (magnification, $\mathrm{x} 400$; visualisation of positive reaction with 3,3'-diaminobenzidine; samples labelled in the same manner). MMP9 expression was evaluated in tumor cells and in stromal cells. (A) Strong expression in tumor cells (black arrows) and stromal cells (red arrows). (B) Moderate positivity in tumor cells (black arrows) and negativity of stromal cells (red arrows). (C) Moderate positivity in tumor cells (black arrows) and strong positivity of stromal cells (red arrows). (D) Negativity in tumor (black arrows) and stromal cells (red arrows).

Enrichment of CTC from peripheral blood by depleting CD $45^{+}$ cells was performed using the Rossette $\operatorname{Sep}^{\mathrm{TM}}$ kit (15162; Stemcell Technologies, Inc.), as previously described $(37,38)$. Briefly, RNA isolated from CD45-depleted peripheral blood samples were transcribed into cDNA, which was subjected to RT-qPCR analysis to assess the expression levels of epithelial-to-mesenchymal transition (EMT-TF) genes, including TWIST1, SNAIL1, SLUG and ZEB1. Compared with healthy donors, patient samples with higher EMT-TF gene transcript levels were classified as CTC EMT positive, based on the preclinical study and human sample testing. The highest expression values in healthy donors were used as a cut-off value to determine CTC positivity (39).

Statistical analysis. Patient characteristics were summarized using the median (range) values for continuous variables and frequency (percentage) for categorical variables. The distribution of MMP9 histoscore was significantly different from the normal distribution (Shapiro-Wilk test), thus non-parametric tests were used for analyses. Mann-Whitney U test was used to compare the differences in distributions of MMP9 expression between two groups of patients with PBC, whereby MMP9 expression was categorized as absent or present. Fisher's exact test or the $\chi^{2}$ test were used where appropriate.

The median follow-up period was estimated as a median observation time among all patients and among those still alive at the time of their last follow-up. Disease-free survival (DFS) was calculated from the date of CTCs measurement to the date of disease recurrence (locoregional or distant), secondary cancer, death or last follow-up. DFS was estimated using the
Kaplan-Meier product limit method and log-rank test. Two-sided $\mathrm{P}<0.05$ was considered to indicate a statistically significant difference. Statistical analyses were performed using NCSS 11 statistical software (2016; NCSS, LLC.; ncss.com/software/ncss).

\section{Results}

Patient characteristics. The present study enrolled 318 patients with PBC. The median age of the assessed cohort was 60 years (age range, 25-83 years). The majority of patients had node negative $(60.1 \%)$ and hormone positive (83.6\%) tumors; 48/318 patients $(15.1 \%)$ had a HER-2/neu amplified status. Patient characteristics are summarized in Table I.

CTCs detection. To establish overexpression of the EMT-inducing TF gene transcripts in patients with PBC, the expression levels were compared between patient samples and healthy donors, as previously described (39). Among the patient samples, CTCs were detected in 83 patients $(26.1 \%)$. CTCs with only epithelial markers were detected in the peripheral blood of 34 patients (10.7\%), while CTCs with an EMT phenotype were present in 56 patients (17.6\%).

Association between MMP9 expression, and patients/tumor characteristic and CTCs. MMP9 protein expression in tumor cells was assessed in all patients $(n=318)$ (Fig. 1). However, pathologists were unable to detect stromal cells in 9/318 tumor tissues due to the small sample size, which only constituted tumor cells. Thus, MMP9 expression in stroma was only assessed in 309 patients. MMP9 expression intensity at least 1+ 
A

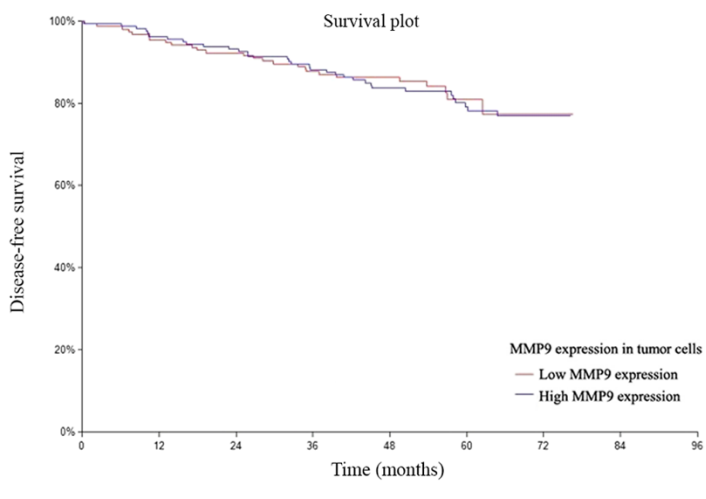

$\mathrm{B}$

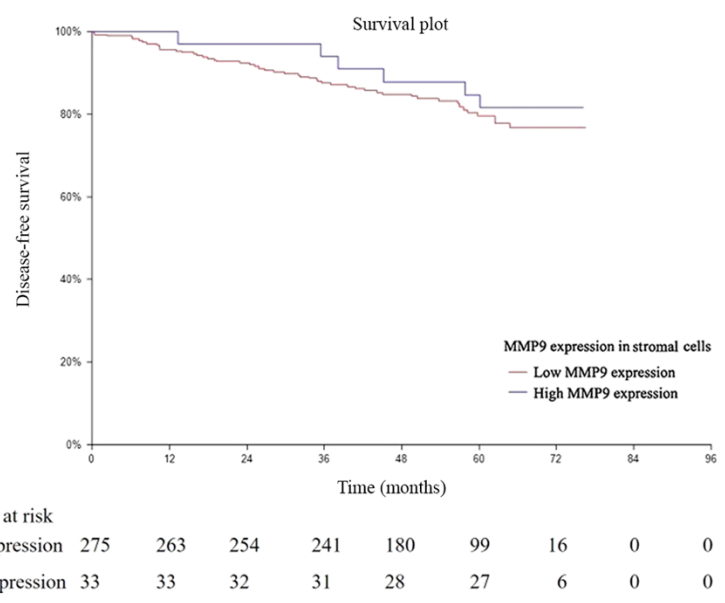

$\begin{array}{llllllllll}\text { Low expression } & 275 & 263 & 254 & 241 & 180 & 99 & 16 & 0 & 0 \\ \text { High expression } & 33 & 33 & 32 & 31 & 28 & 27 & 6 & 0 & 0\end{array}$

Patients at risk

$\begin{array}{lrrrrlrrrr}\text { Low expression } & 155 & 148 & 143 & 136 & 92 & 47 & 9 & 0 & 0 \\ \text { High expression } & 162 & 156 & 151 & 143 & 120 & 80 & 13 & 0 & 0\end{array}$

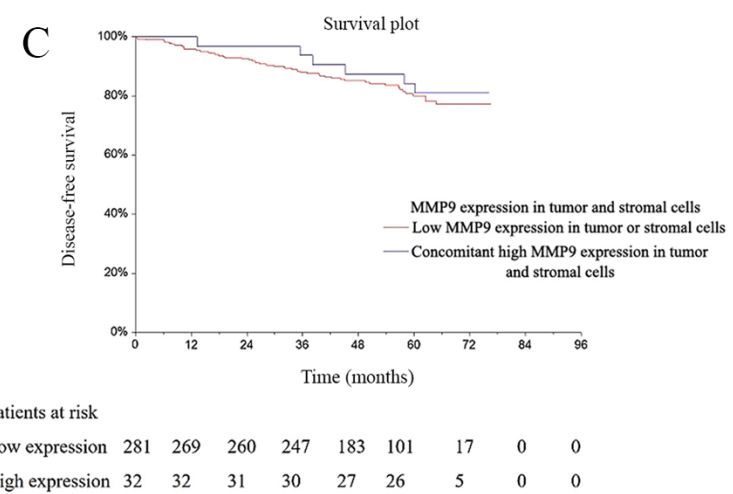

Figure 2. Disease-free survival in all patient groups according to MMP9 expression. (A) Tumor cells ( $\mathrm{P}=0.864)$ and $(\mathrm{B})$ tumor associated stroma ( $\mathrm{P}=0.547)$ results are presented. (C) Patients with concomitant high MMP9 expression in tumor and stromal cells $(\mathrm{P}=0.573)$ results are presented .

and higher was detected in 255 samples (80.2\%) in breast tumor cells and in 307 samples $(99.4 \%)$ of tumor associated stroma $(\mathrm{P}<0.00001)$. The mean $\mathrm{WH} \pm$ standard error of the mean (SEM) for MMP9 expression was significantly higher in breast tumor cells compared with tumor associated stroma (132.0 \pm 5.2 vs. $50.8 \pm 3.7 ; \mathrm{P}<0.00001)$. The association between MMP9 expression in tumor cells and clinicopathological characteristics, as well as its association with CTCs are presented in Table II. The results demonstrated that elevated MMP9 expression was significantly associated with EP/PR positive breast cancer cells (mean $\mathrm{WH} \pm \mathrm{SEM}=137.6 \pm 5.6$ vs. 103.4 $\pm 12.8, \mathrm{P}=0.011)$ and low proliferating tumors (Ki67 <20\%) (mean $\mathrm{WH} \pm \mathrm{SEM}=141.1 \pm 6.7$ vs. $117.9 \pm 8.1, \mathrm{P}=0.018$ ), while elevated MMP9 expression in tumor associated stroma was associated with hormone receptor (EP/PR) status (mean $\mathrm{WH} \pm \mathrm{SEM}=54.6 \pm 4.0$ vs. $30.7 \pm 9.1, \mathrm{P}=0.021$ ) (Table III). In our analysis, there was found any association between MMP9 expression in breast cancer cells, or in tumor associated stroma and CTCs.

Prognostic value of MMP9 in PBC. The median follow-up time was 54.9 months (range, 0.2-76.6 months). In the assessed cohort, 61 patients (19.2\%) experienced a disease progression during follow-up. Among the subgroup of patients where MMP9 expression in tumor associated stroma was assessed $(\mathrm{n}=309)$, the median follow-up time was 55.3 months (range, 0.2-76.6), and 59 patients (19.1\%) experienced a DFS event.
Due to insufficiency of overall survival data, only DFS data are presented in the present study.

Univariate analysis was performed to determine the prognostic value of MMP9 in PBC cells [hazard ratio $(\mathrm{HR})=0.96$; 95\% confidence interval (CI), 0.58-1.59; $\mathrm{P}=0.864$; Fig. 2A], as well as in tumor associated stroma $(\mathrm{HR}=1.29 ; 95 \% \mathrm{CI}$, 0.60-2.78; $\mathrm{P}=0.547$; Fig. 2B). Exploratory subgroup analysis was performed to determine a potential subgroup-related prognostic value of MMP9 (Tables IV and V). In addition, also the univariate analysis in group of patients with concomitant high MMP9 expression in tumor and stromal cells was carried out. However, no prognostic value was found using this analysis ( $\mathrm{HR}=1.27,95 \% \mathrm{CI} 0.59-2.75, \mathrm{P}=0.573)$ (Fig. 2C). The results demonstrated that low MMP9 expression in tumor cells was associated with better DFS in hormone receptor (ER/PR) negative and triple negative patients with $\mathrm{PBC}(\mathrm{HR}=0.33$; 95\% CI, 0.12-0.93; $\mathrm{P}=0.025$; Fig. 3A) and ( $\mathrm{HR}=0.17$; $95 \% \mathrm{CI}$, 0.05-0.57; $\mathrm{P}=0.003$; Fig. 3B), respectively. Notably, the prognostic value of MMP9 in tumor cells was also observed in the CTC_EMT-positive subgroup of patients $(\mathrm{HR}=0.40$; 95\% CI, 0.16-0.95; P=0.047; Fig. 3C). Among the subgroup of patients where MMP9 expression in tumor associated stroma was assessed, the prognostic value of MMP9 was observed in the hormone receptor $(\mathrm{ER} / \mathrm{PR})$ negative subgroup of patients $(\mathrm{HR}=0.14 ; 95 \% \mathrm{CI}, 0.00-4.81 ; \mathrm{P}=0.002$; Fig. 4A), triple negative $(\mathrm{HR}=0.12 ; 95 \% \mathrm{CI}, 0.00-4.89 ; \mathrm{P}=0.001$; Fig. 4B). In addition, among the subgroup of CTC_EMT positive patients 
A

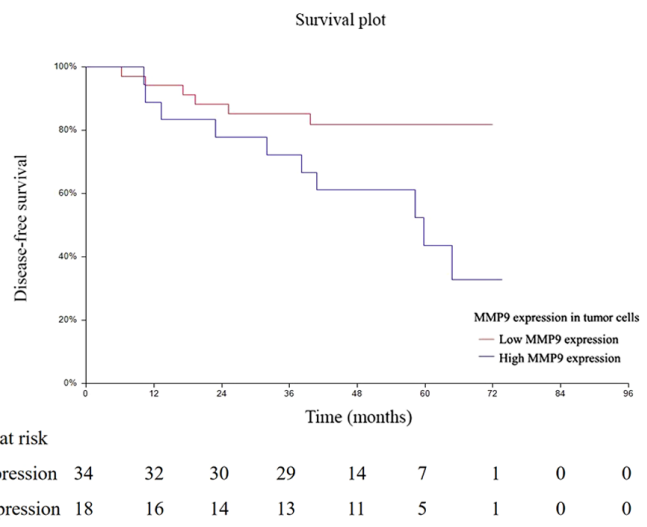

$\mathrm{B}$

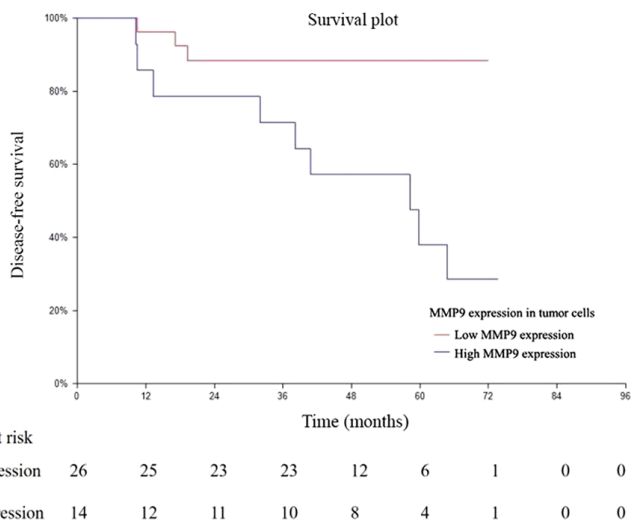

$\mathrm{C}$

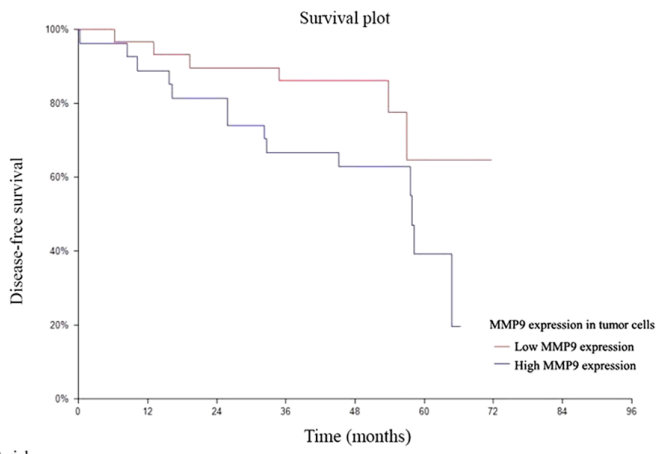

Patients at risk

$\begin{array}{llllllllll}\text { Low expression } & 29 & 28 & 26 & 25 & 15 & 5 & 0 & 0 & 0 \\ \text { High expression } & 27 & 24 & 22 & 18 & 15 & 5 & 0 & 0 & 0\end{array}$

Figure 3. Kaplan-Meier disease-free survival analysis. Disease-free survival according to MMP9 expression in tumor cells of (A) hormone-negative (P=0.025), (B) triple-negative ( $\mathrm{P}=0.003)$, (C) CTC EMT-positive ( $\mathrm{P}=0.047)$ and (D) CTC EP-positive ( $\mathrm{P}=0.675)$ patients is presented. CTC, circulating tumor cells; EMT, epithelial-to-mesenchymal transition; EP, epithelial-positive.

A

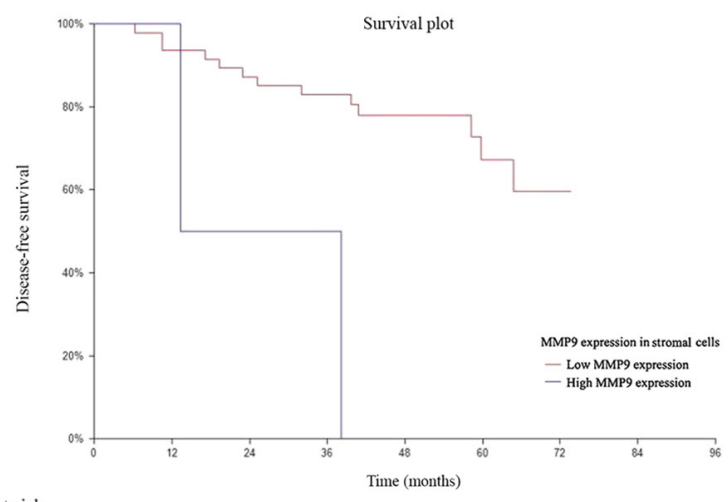

Patients at risk

$\begin{array}{llllllllll}\text { Low expression } & 47 & 44 & 41 & 39 & 23 & 12 & 2 & 0 & 0 \\ \text { High expression } & 2 & 2 & 1 & 1 & 0 & 0 & 0 & 0 & 0\end{array}$
B

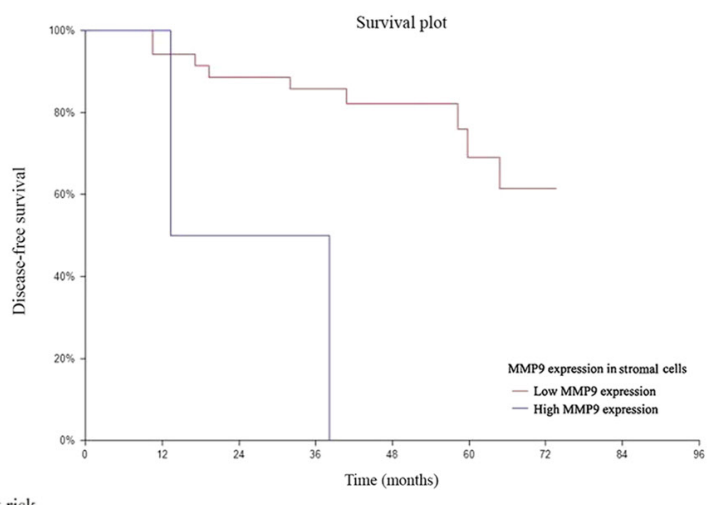

Patients at risk

$\begin{array}{llllllllll}\text { Low expression } & 35 & 33 & 31 & 30 & 18 & 10 & 2 & 0 & 0 \\ \text { High expression } & 2 & 2 & 1 & 1 & 0 & 0 & 0 & 0 & 0\end{array}$

Figure 4. Kaplan-Meier disease-free survival analysis. Disease-free survival according to MMP9 expression in stromal cells of (A) hormone-negative $(\mathrm{P}=0.002),(\mathrm{B})$ triple-negative $(\mathrm{P}=0.001)$. CTC, circulating tumor cells; EMT, epithelial-to-mesenchymal transition

was progression of the disease documented in 1 of 2 patients with high MMP9 expression in stromal cells compared to 22 of 51 patients with low MMP9 expression within 4-years follow up. In subgroup of the CTC_EP positive patients 2 of 4 patient with high MMP9 expression in stromal cells experienced progression of disease compared to 6 of 22 patient with low MMP9 expression after 4-years follow up.

Notably, combinatorial survival analysis of CTC_EMT and MMP9 expression in tumor cells demonstrated that
CTC_EMT positive patients with high MMP9 expression had a significantly shorter DFS compared with CTC_EMT negative patients $(\mathrm{P}<0.00001$; Fig. 5).

\section{Discussion}

MMPs represent a large family of proteolytic enzymes of the extracellular matrix that are involved in extracellular matrix degradation, tumor cell invasion, metastasis and 
Table I. Patient characteristics.

\begin{tabular}{|c|c|c|c|c|c|c|c|}
\hline \multirow{3}{*}{ Characteristic } & \multirow{3}{*}{$\frac{\mathrm{n}(\%)}{318(100.0)}$} & & \\
\hline & & \multirow[b]{2}{*}{ Characteristic } & \multicolumn{5}{|c|}{ MMP9 expression in tumor cells } \\
\hline & & & $\mathrm{N}$ & Mean & SEM & Median & P-value \\
\hline $\begin{array}{l}\text { Invasive ductal carcinoma } \\
\text { Invasive lobular carcinoma } \\
\text { Other histological subtypes }\end{array}$ & $\begin{aligned} 272 & (85.5) \\
32 & (10.1) \\
14 & (4.4)\end{aligned}$ & $\begin{array}{l}\text { MMP9 expression } \\
\text { weighted histoscore } \\
\text { Histology }\end{array}$ & 318 & 132.0 & 5.2 & 150 & $\begin{array}{c}\text { NA } \\
0.081\end{array}$ \\
\hline $\begin{array}{l}\text { Grade } \\
\text { Low and intermediate }\end{array}$ & $200(62.9)$ & $\begin{array}{l}\text { Invasive ductal } \\
\text { carcinoma }\end{array}$ & 272 & 136.0 & 5.6 & 150 & \\
\hline High grade & $110(34.6)$ & Other & 46 & 108.6 & 13.6 & 100 & \\
\hline Unknown & $8(2.5)$ & Grade & & & & & 0.242 \\
\hline $\begin{array}{l}\text { T stage } \\
\text { T1 } \\
\text { T2 and more }\end{array}$ & $\begin{array}{l}218(68.6) \\
100(31.4)\end{array}$ & $\begin{array}{l}\text { Low and intermediate } \\
\text { High grade } \\
\text { Unknown }\end{array}$ & $\begin{array}{r}200 \\
110 \\
8\end{array}$ & $\begin{array}{r}135.1 \\
130.1 \\
80.0\end{array}$ & $\begin{array}{r}6.5 \\
8.8 \\
32.7\end{array}$ & $\begin{array}{r}150 \\
110 \\
0\end{array}$ & \\
\hline $\begin{array}{l}\text { N stage } \\
\text { N0 } \\
\text { N1mi } \\
\text { N1 } \\
\text { N2 } \\
\text { N3 } \\
\text { Unknown }\end{array}$ & $\begin{array}{c}191(60.1) \\
10(3.1) \\
68(21.4) \\
27(8.5) \\
19(6.0) \\
3(0.9)\end{array}$ & $\begin{array}{l}\text { T-stage } \\
\text { T1 } \\
>\mathrm{T} 1 \\
\mathrm{~N} \text { stage } \\
\mathrm{N} 0 \\
\mathrm{~N}^{+} \\
\text {Unknown }\end{array}$ & $\begin{array}{r}201 \\
114 \\
3\end{array}$ & $\begin{array}{r}135.4 \\
127.1 \\
90.0\end{array}$ & $\begin{array}{r}6.5 \\
8.7 \\
53.6\end{array}$ & $\begin{array}{l}150 \\
150 \\
100\end{array}$ & 0.468 \\
\hline $\begin{array}{l}\text { Hormone receptor status (cut-off 1\%) } \\
\text { Negative for both } \\
\text { Positive for either }\end{array}$ & $\begin{array}{r}52(16.4) \\
266(83.6)\end{array}$ & $\begin{array}{l}\text { Hormone receptor } \\
\text { status (cut-off 1\%) } \\
\text { Negative for both } \\
\text { Positive for either }\end{array}$ & $\begin{array}{r}52 \\
266\end{array}$ & $\begin{array}{l}103.4 \\
137.6\end{array}$ & $\begin{array}{r}12.8 \\
5.6\end{array}$ & $\begin{array}{l}100 \\
150\end{array}$ & 0.011 \\
\hline $\begin{array}{l}\text { HER2 status } \\
\text { Negative } \\
\text { Positive }\end{array}$ & $\begin{array}{r}270(84.9) \\
48(15.1)\end{array}$ & $\begin{array}{l}\text { HER2 status } \\
\text { Negative } \\
\text { Positive }\end{array}$ & $\begin{array}{r}270 \\
48\end{array}$ & $\begin{array}{l}131.4 \\
135.7\end{array}$ & $\begin{array}{r}5.6 \\
13.4\end{array}$ & $\begin{array}{l}150 \\
150\end{array}$ & 0.792 \\
\hline $\begin{array}{l}\text { Ki67 status } \\
<20 \% \\
\geq 20 \% \\
\text { Unknown }\end{array}$ & $\begin{array}{c}189(59.4) \\
128(40.3) \\
1(0.3)\end{array}$ & $\begin{array}{l}\text { Ki67 status } \\
\text { (cut-off 20\%) } \\
<20 \% \\
\geq 20 \%\end{array}$ & $\begin{array}{l}189 \\
128\end{array}$ & $\begin{array}{l}141.0 \\
117.9\end{array}$ & $\begin{array}{l}6.7 \\
8.1\end{array}$ & $\begin{array}{l}170 \\
110\end{array}$ & 0.018 \\
\hline $\begin{array}{l}\text { Molecular subtype } \\
\text { Luminal A } \\
\text { Luminal B } \\
\text { HER2 }^{+} \\
\text {Triple negative } \\
\text { Unknown }\end{array}$ & $\begin{aligned} 166 & (52.2) \\
99 & (31.1) \\
13 & (4.1) \\
39 & (12.3) \\
1 & (0.3)\end{aligned}$ & $\begin{array}{l}\text { Unknown } \\
\text { Molecular subtype } \\
\text { Luminal A } \\
\text { Luminal B } \\
\text { HER2 }^{+} \\
\text {Triple negative }\end{array}$ & $\begin{array}{r}166 \\
99 \\
13 \\
39\end{array}$ & $\begin{array}{l}138.6 \\
134.8 \\
106.2 \\
102.4\end{array}$ & $\begin{array}{r}7.2 \\
9.3 \\
25.6 \\
14.8\end{array}$ & $\begin{array}{l}160 \\
150 \\
100 \\
100\end{array}$ & 0.0711 \\
\hline $\begin{array}{l}\text { P53 status } \\
\text { Negative } \\
\text { Positive } \\
\text { Unknown }\end{array}$ & $\begin{array}{c}193(60.7) \\
124(39.0) \\
1(0.3)\end{array}$ & $\begin{array}{l}\text { Unknown } \\
\text { P53 status } \\
\text { Negative } \\
\text { Positive } \\
\text { Unknown }\end{array}$ & $\begin{array}{r}193 \\
124 \\
1\end{array}$ & $\begin{array}{r}131.1 \\
134.1 \\
50.0\end{array}$ & $\begin{array}{r}6.7 \\
8.3 \\
92.9\end{array}$ & $\begin{array}{r}150 \\
150 \\
50\end{array}$ & 0.632 \\
\hline $\begin{array}{l}\text { BCL-2 status } \\
\text { Negative } \\
\text { Positive } \\
\text { Unknown }\end{array}$ & $\begin{array}{r}92(28.9) \\
225(70.8) \\
1(0.3)\end{array}$ & $\begin{array}{l}\text { BCL-2 } \\
\text { Negative } \\
\text { Positive } \\
\text { Unknown }\end{array}$ & $\begin{array}{r}92 \\
225 \\
1\end{array}$ & $\begin{array}{l}126.0 \\
134.0 \\
250.0\end{array}$ & $\begin{array}{r}9.7 \\
6.2 \\
92.7\end{array}$ & $\begin{array}{l}110 \\
150 \\
250\end{array}$ & 0.229 \\
\hline $\begin{array}{l}\text { CTC EP } \\
\text { Negative } \\
\text { Positive }\end{array}$ & $\begin{array}{l}235(73.9) \\
27(8.5)\end{array}$ & $\begin{array}{l}\text { CTC EP } \\
\text { Negative } \\
\text { Positive }\end{array}$ & $\begin{array}{r}235 \\
27\end{array}$ & $\begin{array}{l}134.1 \\
138.1\end{array}$ & $\begin{array}{r}6.0 \\
17.5\end{array}$ & $\begin{array}{l}150 \\
150\end{array}$ & 0.851 \\
\hline $\begin{array}{l}\text { CTC EMT } \\
\text { Negative } \\
\text { Positive }\end{array}$ & $\begin{array}{r}235(73.9) \\
56(17.6)\end{array}$ & $\begin{array}{l}\text { CTC EMT } \\
\text { Negative } \\
\text { Positive }\end{array}$ & $\begin{array}{r}235 \\
56\end{array}$ & $\begin{array}{l}134.1 \\
120.4\end{array}$ & $\begin{array}{r}6.1 \\
12.4\end{array}$ & $\begin{array}{l}150 \\
135\end{array}$ & 0.300 \\
\hline $\begin{array}{l}\text { CTC any } \\
\text { Negative } \\
\text { Positive }\end{array}$ & $\begin{array}{r}235(73.9) \\
83(26.1)\end{array}$ & $\begin{array}{l}\text { CTC any } \\
\text { Negative } \\
\text { Positive }\end{array}$ & $\begin{array}{r}235 \\
83\end{array}$ & $\begin{array}{l}134.1 \\
126.1\end{array}$ & $\begin{array}{r}6.1 \\
10.2\end{array}$ & $\begin{array}{l}150 \\
150\end{array}$ & 0.472 \\
\hline $\begin{array}{l}\text { CTC, circulating tumor cells; EMT, epithelia } \\
\text { EP, epithelial-positive. }\end{array}$ & mal transition; & NA, not applicable; EP, epi & thelial- & $\begin{array}{l}\text { Г, epitheli } \\
\text { positive. }\end{array}$ & l-to-1 & enchymal & transition; \\
\hline
\end{tabular}


Table III. Association between MMP9 expression in stromal cells, patients, tumour characteristics and circulating tumor cells.

\begin{tabular}{|c|c|c|c|c|c|}
\hline \multirow[b]{2}{*}{ Characteristic } & \multicolumn{5}{|c|}{ MMP9 expression in stromal cells } \\
\hline & $\mathrm{N}$ & Mean & SEM & Median & P-value \\
\hline $\begin{array}{l}\text { MMP9 expression } \\
\text { weighted histoscore }\end{array}$ & 309 & 50.8 & 3.7 & 25 & NA \\
\hline $\begin{array}{l}\text { Histology } \\
\text { Invasive ductal } \\
\text { carcinoma }\end{array}$ & 266 & 51.9 & 4.0 & 30 & 0.434 \\
\hline Other & 43 & 44.2 & 9.8 & 20 & \\
\hline $\begin{array}{l}\text { Grade } \\
\text { Low and intermediate } \\
\text { High grade } \\
\text { Unknown }\end{array}$ & $\begin{array}{r}194 \\
108 \\
7\end{array}$ & $\begin{array}{l}50.9 \\
51.7 \\
34.3\end{array}$ & $\begin{array}{r}4.6 \\
6.2 \\
24.4\end{array}$ & $\begin{array}{r}30 \\
20 \\
0\end{array}$ & 0.489 \\
\hline $\begin{array}{l}\text { T-stage } \\
\text { T1 } \\
>\mathrm{T} 1\end{array}$ & $\begin{array}{r}213 \\
96\end{array}$ & $\begin{array}{l}52.6 \\
46.8\end{array}$ & $\begin{array}{l}4.4 \\
6.6\end{array}$ & $\begin{array}{l}25 \\
25\end{array}$ & 0.469 \\
\hline $\begin{array}{l}\text { N stage } \\
\text { N0 } \\
\mathrm{N}^{+} \\
\text {Unknown }\end{array}$ & $\begin{array}{r}197 \\
110 \\
2\end{array}$ & $\begin{array}{l}54.9 \\
43.5 \\
50.0\end{array}$ & $\begin{array}{r}4.6 \\
6.1 \\
45.6\end{array}$ & $\begin{array}{l}30 \\
20 \\
50\end{array}$ & 0.536 \\
\hline $\begin{array}{l}\text { Hormone receptor } \\
\text { status (cut-off } 1 \% \text { ) } \\
\text { Negative for both } \\
\text { Positive for either }\end{array}$ & $\begin{array}{r}49 \\
260\end{array}$ & $\begin{array}{l}30.7 \\
54.6\end{array}$ & $\begin{array}{l}9.1 \\
4.0\end{array}$ & $\begin{array}{r}5 \\
30\end{array}$ & 0.021 \\
\hline $\begin{array}{l}\text { HER2 status } \\
\text { Negative } \\
\text { Positive }\end{array}$ & $\begin{array}{r}263 \\
46\end{array}$ & $\begin{array}{l}50.7 \\
51.6\end{array}$ & $\begin{array}{l}4.0 \\
9.5\end{array}$ & $\begin{array}{l}20 \\
30\end{array}$ & 0.872 \\
\hline $\begin{array}{l}\text { Ki67 status } \\
\text { (cut-off 20\%) } \\
<20 \% \\
\geq 20 \%\end{array}$ & $\begin{array}{l}183 \\
126\end{array}$ & $\begin{array}{l}56.3 \\
42.9\end{array}$ & $\begin{array}{l}4.8 \\
5.7\end{array}$ & $\begin{array}{l}30 \\
20\end{array}$ & 0.137 \\
\hline $\begin{array}{l}\text { Molecular subtype } \\
\text { Luminal A } \\
\text { Luminal B } \\
\text { HER2 }^{+} \\
\text {Triple negative }\end{array}$ & $\begin{array}{r}163 \\
97 \\
12 \\
37\end{array}$ & $\begin{array}{l}57.0 \\
50.5 \\
15 \\
35.8\end{array}$ & $\begin{array}{l}68.7 \\
62.0 \\
24.3 \\
55.7\end{array}$ & $\begin{array}{r}30 \\
30 \\
0 \\
5\end{array}$ & 0.094 \\
\hline $\begin{array}{l}\text { P53 status } \\
\text { Negative } \\
\text { Positive } \\
\text { Unknown }\end{array}$ & $\begin{array}{r}188 \\
120 \\
1\end{array}$ & $\begin{array}{r}48.1 \\
55.5 \\
0.0\end{array}$ & $\begin{array}{r}4.7 \\
5.9 \\
64.5\end{array}$ & $\begin{array}{r}30 \\
20 \\
0\end{array}$ & 0.537 \\
\hline $\begin{array}{l}\text { BCL-2 } \\
\text { Negative } \\
\text { Positive }\end{array}$ & $\begin{array}{r}88 \\
221\end{array}$ & $\begin{array}{l}47.9 \\
52.0\end{array}$ & $\begin{array}{l}6.9 \\
4.3\end{array}$ & $\begin{array}{l}30 \\
20\end{array}$ & 0.995 \\
\hline $\begin{array}{l}\text { CTC EP } \\
\text { Negative } \\
\text { Positive }\end{array}$ & $\begin{array}{r}229 \\
27\end{array}$ & $\begin{array}{l}54.4 \\
41.3\end{array}$ & $\begin{array}{r}4.1 \\
12.8\end{array}$ & $\begin{array}{l}30 \\
20\end{array}$ & 0.350 \\
\hline $\begin{array}{l}\text { CTC EMT } \\
\text { Negative } \\
\text { Positive }\end{array}$ & $\begin{array}{r}229 \\
53\end{array}$ & $\begin{array}{l}54.4 \\
40.3\end{array}$ & $\begin{array}{c}4.1 \\
10\end{array}$ & $\begin{array}{l}30 \\
10\end{array}$ & 0.400 \\
\hline $\begin{array}{l}\text { CTC any } \\
\text { Negative } \\
\text { Positive }\end{array}$ & $\begin{array}{r}229 \\
80\end{array}$ & $\begin{array}{l}54.4 \\
40.6\end{array}$ & $\begin{array}{l}4.1 \\
7.2\end{array}$ & $\begin{array}{l}30 \\
20\end{array}$ & 0.168 \\
\hline
\end{tabular}

CTC, circulating tumor cells; EP, epithelial; EMT, epithelial-to-mesenchymal transition; NA, not applicable.

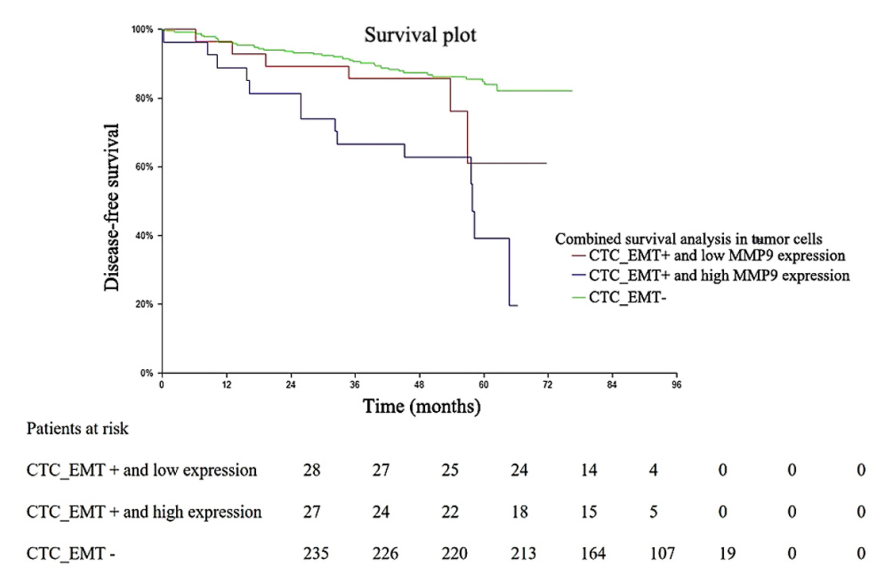

Figure 5. Kaplan-Meier DFS analysis for a combination of CTC EMT and MMP9. CTC EMT positive patients with MMP9 expression had a worse DFS than patients that are CTC EMT negative. $\mathrm{P}<0.00001$. DFS, disease-free survival; CTC, circulating tumor cells; EMT, epithelial-to-mesenchymal transition.

angiogenesis $(19,40-42)$. The results of the present study demonstrated that elevated MMP9 expression levels in tumor cells and tumor associated stroma were significantly associated with favorable tumor characteristics. Hormone-positive tumors exhibited significantly higher MMP9 expression in tumor cells, as well as in tumor associated stromal cells. In addition, the results demonstrated an association between increased MMP9 expression and low proliferation index of Ki67. Although the role of MMP9 and its association with breast cancer has been extensively studied, data regarding the prognostic value of MMP9 are inconsistent. On one hand, it has been reported that MMP9 expression is associated with a shorter relapse-free survival time in patients with primary breast tumours $(26,29,43,44)$. The association between upregulated MMP9 expression and an increased risk of overall survival and relapse-free survival in breast cancer has also been confirmed via meta-analyses by Song et al (45) and Ren et al (46). Conversely, some studies have identified MMP-9 as a favourable prognostic marker for breast cancer $(9,47)$.

The results of the present study demonstrated a significant association between high MMP9 expression in tumour cells and poor DFS in hormone receptor negative, triple negative, as well as in the CTC_EMT-positive subgroup of patients with early breast cancer. Analysis of stromal cells exhibited this association in the hormone receptor negative and triple negative subgroups of patients.

These results are in concordance with previous studies, confirming the association between MMP9 expression and a shorter progression time, particularly in patients with basal-like or triple negative breast cancer $(48,49)$. Controversy regarding the association between MMP9 expression and clinical outcomes in different types of malignant tumors, including breast cancer, suggests the presence of active and inactive forms of MMP9. MMPs are secreted in the form of inactive proenzymes, whose activation is mediated via different molecular mechanisms $(20,21)$. Thus, the level of active MMP9 in stromal cells and tumor cells may vary, which will subsequently account for the differences in clinical outcomes (50).

Notably, the results of the present study demonstrated the prognostic value of MMP9 in the CTC_EMT-positive 
Table IV. Univariate analysis for disease-free survival according to MMP9 expression in tumor cells.

\begin{tabular}{|c|c|c|c|c|c|c|c|c|c|c|c|}
\hline \multirow{2}{*}{ Characteristic } & \multirow{2}{*}{$\mathrm{N}$} & \multirow{2}{*}{ HR } & \multirow{2}{*}{$\begin{array}{c}95 \% \\
\text { Low CI }\end{array}$} & \multirow{2}{*}{$\begin{array}{c}95 \% \\
\text { High CI }\end{array}$} & \multirow{2}{*}{$\mathrm{P}$-value } & Characteristic & $\mathrm{N}$ & HR & Low CI & High CI & P-value \\
\hline & & & & & & P53 positive $^{\mathrm{c}}$ & & & & & 0.829 \\
\hline Overall & & & & & 0.864 & Low MMP9 expression & 59 & 1.11 & 0.43 & 2.82 & \\
\hline Low MMP9 expression & 156 & 0.96 & 0.58 & 1.59 & & High MMP9 expression & 65 & & & & \\
\hline High MMP9 expression & 162 & & & & & BCL2 negative ${ }^{c}$ & & & & & 0.124 \\
\hline Invasive ductal carcinoma & & & & & 0.550 & Low MMP9 expression & 51 & 0.53 & 0.24 & 1.18 & \\
\hline Low MMP9 expression & 126 & 0.84 & 0.48 & 1.47 & & High MMP9 expression & 41 & & & & \\
\hline High MMP9 expression & 146 & & & & & BCL2 positive ${ }^{c}$ & & & & & 0.445 \\
\hline Other histology & & & & & 0.335 & Low MMP9 expression & 105 & 1.29 & 0.67 & 2.49 & \\
\hline Low MMP9 expression & 30 & 2.12 & 0.55 & 8.17 & & High MMP9 expression & 120 & & & & \\
\hline High MMP9 expression & 16 & & & & & CTC EP negative & & & & & 0.387 \\
\hline Intermediate/low grade ${ }^{\mathrm{a}}$ & & & & & 0.901 & Low MMP9 expression & 115 & 1.33 & 0.69 & 2.57 & \\
\hline Low MMP9 expression & 93 & 0.95 & 0.44 & 2.07 & & High MMP9 expression & 120 & & & & \\
\hline High MMP9 expression & 107 & & & & & CTC EP positive & & & & & 0.675 \\
\hline High grade ${ }^{8 \text { pts NA }}$ & & & & & 0.518 & Low MMP9 expression & 12 & 1.52 & 0.20 & 11.24 & \\
\hline Low MMP9 expression & 58 & 0.80 & 0.40 & 1.58 & & High MMP9 expression & 15 & & & & \\
\hline High MMP9 expression & 52 & & & & & CTC EMT negative & & & & & 0.387 \\
\hline T1 stage & & & & & 0.936 & Low MMP9 expression & 115 & 1.33 & 0.69 & 2.47 & \\
\hline Low MMP9 expression & 99 & 0.97 & 0.48 & 1.98 & & High MMP9 expression & 120 & & & & \\
\hline High MMP9 expression & 119 & & & & & CTC EMT positive & & & & & 0.047 \\
\hline $\mathrm{T} 2$ stage and higher & & & & & 0.484 & Low MMP9 expression & 29 & 0.40 & 0.16 & 0.95 & \\
\hline Low MMP9 expression & 57 & 0.77 & 0.37 & 1.60 & & High MMP9 expression & 27 & & & & \\
\hline High MMP9 expression & 43 & & & & & CTC any negative & & & & & 0.387 \\
\hline N0 stage ${ }^{\mathrm{b}}$ & & & & & 0.844 & $\begin{array}{l}\text { Low MMP9 expression } \\
\text { High MMP9 expression }\end{array}$ & $\begin{array}{l}115 \\
120\end{array}$ & 1.33 & 0.69 & 2.57 & \\
\hline $\begin{array}{l}\text { Low MMP9 expression } \\
\text { High MMP9 expression }\end{array}$ & $\begin{array}{r}99 \\
102\end{array}$ & 0.92 & 0.41 & 2.09 & & CTC any positive & & & & & 0.113 \\
\hline $\begin{array}{l}\mathrm{N}^{+} \text {stage }^{\mathrm{b}} \\
\text { Low MMP9 expression }\end{array}$ & 55 & 1.04 & 0.54 & 2.00 & 0.909 & $\begin{array}{l}\text { Low MMP9 expression } \\
\text { High MMP9 expression }\end{array}$ & $\begin{array}{l}41 \\
42\end{array}$ & 0.51 & 0.23 & 1.14 & \\
\hline
\end{tabular}

Table IV. Continued.

Characteristic

53 positive $^{c}$

$\begin{array}{lllll}\text { Low MMP9 expression } & 59 & 1.11 & 0.43 & 2.82\end{array}$

High MMP9 expression 65

45

387

675
${ }^{a}$ Data not available in 8 patients; ${ }^{b}$ data not available in 3 patients; 'data not

0.539 available in one patient; ER, estrogen receptor; PR, progesterone receptor; CTC, circulating tumor cells; EMT, epithelial-to-mesenchymal transition; EP, epithelial; HZ, hazard ratio; CI, confidence interval; NA, not applicable.

0.025

$\begin{array}{lllll}\text { Low MMP9 expression } & 34 & 0.33 & 0.12 & 0.93 \\ \text { High MMP9 expression } & 18 & & & \end{array}$

HER positive

$\begin{array}{lllll}\text { Low MMP9 expression } & 22 & 1.22 & 0.42 & 3.49\end{array}$ subgroup of patients. Generally, ETM is considered a devel-
opmental process, facilitating the resistance to apoptosis and increased invasion, and is closely associated with development of a cancer stem cell phenotype $(19,51)$ This machinery can $\begin{array}{lll}\text { HER negative } & 0.741\end{array}$ be directly induced by MMPs in the target epithelial cells. Expression of proteases, including MMPs is upregulated during reorganization of ECM in EMT. In addition, the process of MMP-induced EMT has been best characterized in mammary epithelial cells $(52,53)$. According to the results of the present study, there was no significant association between any subpopulations of CTCs and MMP9 expression.

0.149 Contrary to MMP1, MMP9 does not actively participate in the release of CTCs into the blood stream of patients with PBC (31). However, these changes may result in the resistance 0.003 to therapy, and development of a cancer stem cell phenotype closely associated with poor DFS. Given the limited treatment options for these subgroups of patients (triple-negative 0.735 and CTC_EMT-positive PBC), MMP9 may potentially offer a novel therapeutic target. In addition, the results from the combinatorial survival analysis demonstrated that CTC_EMT $\begin{array}{lllll}\text { Low MMP9 expression } & 96 & 0.90 & 0.49 & 1.65\end{array}$ High MMP9 expression 97
Triple negative ${ }^{c}$

$\begin{array}{lllll}\text { Low MMP9 expression } & 26 & 0.17 & 0.05 & 0.57 \\ \text { High MMP9 expression } & 13 & & & \end{array}$

High MMP9 expression 
Table V. Univariate analysis for disease-free survival according to MMP9 expression in stromal cells.

\begin{tabular}{|c|c|c|c|c|c|c|c|c|c|c|c|}
\hline \multirow{2}{*}{ Characteristic } & \multirow{2}{*}{$\mathrm{N}$} & \multirow{2}{*}{ HR } & \multirow{2}{*}{$\begin{array}{c}95 \% \\
\text { Low CI }\end{array}$} & \multirow{2}{*}{$\begin{array}{c}95 \% \\
\text { High CI }\end{array}$} & \multirow{2}{*}{ P-value } & Characteristic & $\mathrm{N}$ & HR & Low CI & High CI & P-value \\
\hline & & & & & & D53 mocitivac & & & & & 0482 \\
\hline Overall & & & & & 0.547 & Low MMP9 expression & 104 & 1.68 & 0.50 & 5.69 & \\
\hline Low MMP9 expression & 276 & 1.29 & 0.60 & 2.78 & & High MMP9 expression & 16 & & & & \\
\hline High MMP9 expression & 33 & & & & & BCL2 negative & & & & & 0.078 \\
\hline Invasive ductal carcinoma & & & & & 0.458 & Low MMP9 expression & 83 & 0.35 & 0.05 & 2.29 & \\
\hline Low MMP9 expression & 237 & 1.41 & 0.63 & 3.18 & & High MMP9 expression & 5 & & & & \\
\hline High MMP9 expression & 29 & & & & & BCL2 positive & & & & & 0.238 \\
\hline Other histology & & & & & 0.825 & Low MMP9 expression & 193 & 2.00 & 0.81 & 4.96 & \\
\hline Low MMP9 expression & 39 & 0.79 & 0.08 & 7.84 & & High MMP9 expression & 28 & & & & \\
\hline High MMP9 expression & 4 & & & & & CTC EP negative & & & & & 0.143 \\
\hline Intermediate/low grade ${ }^{\mathrm{a}}$ & & & & & 0.970 & Low MMP9 expression & 202 & 2.76 & 1.08 & 7.09 & \\
\hline Low MMP9 expression & 174 & 1.02 & 0.31 & 3.38 & & High MMP9 expression & 27 & & & & \\
\hline High MMP9 expression & 20 & & & & & CTC EP positive & & & & & 0.053 \\
\hline High grade $^{\mathrm{a}}$ & & & & & 0.458 & Low MMP9 expression & 23 & 0.18 & 0.01 & 2.75 & \\
\hline Low MMP9 expression & 96 & 1.56 & 0.57 & 4.24 & & High MMP9 expression & 4 & & & & \\
\hline High MMP9 expression & 12 & & & & & CTC EMT negative & & & & & 0.143 \\
\hline T1 stage & & & & & 0.974 & Low MMP9 expression & 202 & 2.76 & 1.08 & 7.09 & \\
\hline Low MMP9 expression & 189 & 1.02 & 0.36 & 2.90 & & High MMP9 expression & 27 & & & & \\
\hline High MMP9 expression & 24 & & & & & CTC EMT positive & & & & & 0.168 \\
\hline T2 stage and higher & & & & & 0.457 & Low MMP9 expression & 51 & 0.37 & 0.04 & 3.50 & \\
\hline Low MMP9 expression & 87 & 1.71 & 0.54 & 5.43 & & High MMP9 expression & 2 & & & & \\
\hline High MMP9 expression & 9 & & & & & CTC any negative & & & & & 0.143 \\
\hline N0 stage ${ }^{b}$ & & & & & 0.460 & Low MMP9 expression & 202 & 2.76 & 1.08 & 7.09 & \\
\hline Low MMP9 expression & 174 & 1.71 & 0.53 & 5.55 & & High MMP9 expression & 27 & & & & \\
\hline High MMP9 expression & 23 & & & & & CTC any positive & & & & & 0.128 \\
\hline $\mathrm{N}^{+}$stage $^{\mathrm{b}}$ & & & & & 0.871 & Low MMP9 expression & 74 & 0.44 & 0.10 & 1.91 & \\
\hline Low MMP9 expression & 100 & 0.92 & 0.31 & 2.70 & & High MMP9 expression & 6 & & & & \\
\hline
\end{tabular}

High MMP9 expression 10

ER/PR positive for either

$\begin{array}{lllll}\text { Low MMP9 expression } & 229 & 1.67 & 0.71 & 3.88\end{array}$

High MMP9 expression 3

ER/PR negative for both

Low MMP9 expression

High MMP9 expression

HER positive

$\begin{array}{lllll}\text { Low MMP9 expression } \quad 39 & 3.12 & 0.83 & 11.74\end{array}$

High MMP9 expression 7

HER negative

$\begin{array}{lllll}\text { Low MMP9 expression } & 237 & 1.06 & 0.43 & 2.64\end{array}$

High MMP9 expression 26

Ki67 low $(<20 \%)$

$\begin{array}{lllll}\text { Low MMP9 expression } & 159 & 1.67 & 0.50 & 5.53\end{array}$

High MMP9 expression 24

Ki67 high ( $\geq 20 \%)$

$\begin{array}{lllll}\text { Low MMP9 expression } & 117 & 0.80 & 0.26 & 2.50\end{array}$

High MMP9 expression

Triple negative

$\begin{array}{lllll}\text { Low MMP9 expression } & 35 & 0.12 & 0.00 & 4.89\end{array}$

High MMP9 expression 2

P53 negative ${ }^{c}$

$\begin{array}{llll}\text { Low MMP9 expression } & 171 & 1.07 & 0.39\end{array}$

High MMP9 expression 17
Table V. Continued.

Characteristic

482

553 positive

$\begin{array}{lllll}\text { Low MMP9 expression } & 104 & 1.68 & 0.50 & 5.69\end{array}$

High MMP9 expression 16

BCL2 negative

$\begin{array}{lllll}\text { Low MMP9 expression } & 83 & 0.35 & 0.05 & 2.29\end{array}$

BCL2 positive

143

053

143

${ }^{\mathrm{a}}$ Data not available in 7 patients; ${ }^{\mathrm{b}}$ data not available in 2 patients; ${ }^{\mathrm{c}}$ data not available in patient; ER, estrogen receptor; PR, progesterone receptor; CTC, circulating tumor cells; EP, epithelial; EMT, epithelial-to-mesenchymal transition; HZ, hazard ratio; CI, confidence interval; NA, not applicable.

0.002

0.242 positive patients with MMP9 expression in tumor cells had a significantly lower DFS compared with CTC_EMT negative 0.900 marker only in subgroups of patients with high MMP9 expression, while the subgroup of CTC_EMT positive patients, with low MMP9 expression exhibited no effects.

The spectrum of synthetized MMP inhibitors (MMPIs) assessed in clinical trials have demonstrated poor effectiveeffect of MMPIs may be due to their poor selectivity. Previous 0.679 studies have focused on a broad spectrum of MMPs, most of which exert tumorigenic activity. However, it is necessary to take into consideration that some MMPs are characterized 0.001 by antitumorigenic effects. Another reason for MMPIs inefficiency can be due to their administration to unselected groups of patients $(44,56)$. strated the protective role of MMP9 in patients with breast cancer, whereby its increased expression was associated $\begin{array}{lllll}\text { Low MMP9 expression } & 193 & 2.00 & 0.81 & 4.96\end{array}$ patients, suggesting that EMT acts as a negative prognostic ness and serious side effects $(54,55)$. The limited clinical

In conclusion, this prospective translational study demon- 
with favourable tumour characteristics. Thus, as it has been proposed by Pozzi et al (57), inhibition of MMP9 antitumorigenic and antiangiogenic activities may result in a paradoxical increase of tumor angiogenesis and tumor growth. Conversely, the results of the present study demonstrated the association between high MMP9 expression and poor DFS in selected subgroups of patients with $\mathrm{PBC}$, particularly hormone receptor negative and triple negative tumors, as well as in CTC_EMT positive patients. These results suggest that MMP9 exerts different biological roles in HR positive vs. negative tumors, further supporting the concept of different biology of breast cancer subtypes according to their HR status. Thus, assessing MMP9 tumor expression may help identify individuals with increased risk of disease recurrence within the aforementioned subgroups of patients with PBC. However, there were certain limitations to the present study, such as the retrospective design of the study and semi-quantitative IHC analysis used for investigating of MMP9 expression. In addition, the study population represent a homogenous cohort of patients, treatment-naïve, without metastatic disease, in order to avoid the effect of the metastatic site heterogeneity factor on analysed variables.

Further studies are required to develop selective MMPIs against the specific protumorigenic MMPs or protumorigenic activities of selected MMPs. Another strategy may be anticancer therapy with antitumorigenic MMPs or with their antitumorigenic subparts. An example of this phenomenon involves the MMP8 enzyme, whereby high MMP8 expression supresses metastasis, while MMP8 silencing induces tumour progression and metastasis (58-60).

\section{Acknowledgements}

The authors would like to thank Dr Gabriela Sieberova, Dr Jan Macuch, Dr Michal Majercik, Dr Peter Jani and Professor Pavel Babal (all from Department of Pathology, Faculty of Medicine, Comenius University) for their valuable input into IHC evaluation. The authors would also like to thank Ms. Zlatica Pekova (2nd Department of Oncology, Faculty of Medicine, Comenius University, National Cancer Institute) for administrative support, and Ms. Emilia Klincova and Mr. Ludovit Gaspar (both, Department of Pathology, Faculty of Medicine, Comenius University) for their excellent technical assistance.

\section{Funding}

The present study was funded by the Slovak Research and Development Agency (grant no. APVV-16-0010).

\section{Availability of data and materials}

All datasets generated and analyzed during the present study are included in this published article.

\section{Authors' contributions}

KK, ZC, JM, MM and GM conceived and designed the present study. KK performed statistical analysis. ZC and IM performed immunohistochemical analysis. GM, TS and DK were involved in CTC detection. MK, JB and DP were involved in patient accrual and performed breast surgery. KK and MM drafted the initial manuscript, and all authors reviewed it critically for important intellectual content. All authors participated in the acquisition, analysis and interpretation of data. All authors have read and approved the final version of the manuscript for publication.

\section{Ethics approval and consent to participate}

The present study was reviewed and approved by the Institutional Review Board of the National Cancer Institute of Slovakia, Bratislava, Slovakia (approval no. TRU-SK 002; Chair: Professor Michal Mego). Written informed consent was provided by all patients prior to study commencement.

\section{Patient consent for publication}

Not applicable.

\section{Competing interests}

The authors declare that they have no competing interests.

\section{References}

1. Ghoncheh M, Pournamdar Z and Salehiniya H: Incidence and mortality and epidemiology of breast cancer in the world. Asian Pac J Cancer Prev 17: 43-46, 2016.

2. Bray F, Ferlay J, Soerjomataram I, Siegel RL, Torre LA and Jemal A: Global cancer statistics 2018: GLOBOCAN estimates of incidence and mortality worldwide for 36 cancers in 185 countries. CA Cancer J Clin 68: 394-424, 2018.

3. Moreau JE, Anderson K, Mauney JR, Nguyen T, Kaplan DL and Rosenblatt M: Tissue-engineered bone serves as a target for metastasis of human breast cancer in a mouse model. Cancer Res 67: 10304-10308, 2007.

4. Fagan-Solis KD, Schneider SS, Pentecost BT, Bentley BA, Otis CN, Gierthy JF and Arcaro KF: The RhoA pathway mediates MMP-2 and MMP-9-independent invasive behavior in a triple-negative breast cancer cell line. J Cell Biochem 114: 1385-1394, 2013.

5. Malmgren JA, Mayer M, Atwood MK and Kaplan HG: Differential presentation and survival of de novo and recurrent metastatic breast cancer over time: 1990-2010. Breast Cancer Res Treat 167: 579-590, 2018.

6. Fan J, Deng X, Gallagher JW, Huang H, Huang Y, Wen J, Ferrari M, Shen $\mathrm{H}$ and $\mathrm{Hu} \mathrm{Y}$ : Monitoring the progression of metastatic breast cancer on nanoporous silica chips. Philos Trans- Royal Soc, Math Phys Eng Sci 370: 2433-2447, 2012.

7. Bottino J, Gelaleti GB, Maschio LB, Jardim-Perassi BV and de Campos Zuccari DA: Immunoexpression of ROCK-1 and MMP-9 as prognostic markers in breast cancer. Acta Histochem 116: 1367-1373, 2014.

8. Olayide A, Samuel O, Ganiyu R, Moses A, Gafar O, Abiola D, Dapo K and John A: How effective is the treatment of locally advanced and metastatic breast cancer in developing centres?: A retrospective review. Ethiop J Health Sci 25: 337-344, 2015.

9. Scorilas A, Karameris A, Arnogiannaki N, Ardavanis A, Bassilopoulos P, Trangas T and Talieri M: Overexpression of matrix-metalloproteinase- 9 in human breast cancer: A potential favourable indicator in node-negative patients. Br J Cancer 84: 1488-1496, 2001

10. Fidler IJ: Metastasis: Quantitative analysis of distribution and fate of tumor emboli labeled with 125 I-5-iodo-2'-deoxyuridine. J Natl Cancer Inst 45: 773-782, 1970.

11. Lambert AW, Pattabiraman DR and Weinberg RA: Emerging biological principles of metastasis. Cell 168: 670-691, 2017.

12. Nguyen DX, Bos PD and Massagué J: Metastasis: From dissemination to organ-specific colonization. Nat Rev Cancer 9: 274-284, 2009. 
13. Hsiao KC, Shih NY, Fang HL, Huang TS, Kuo CC, Chu PY, Hung YM, Chou SW, Yang YY, Chang GC, et al: Surface $\alpha$-enolase promotes extracellular matrix degradation and tumor metastasis and represents a new therapeutic target. PLoS One 8: e69354, 2013.

14. Wang X, Lu H, Urvalek AM, Li T, Yu L, Lamar J, DiPersio CM, Feustel PJ and Zhao J: KLF8 promotes human breast cancer cell invasion and metastasis by transcriptional activation of MMP9. Oncogene 30: 1901-1911, 2011

15. Ortíz-López L, Morales-Mulia S, Ramírez-Rodríguez G and Benítez-King G: ROCK-regulated cytoskeletal dynamics participate in the inhibitory effect of melatonin on cancer cell migration. J Pineal Res 46: 15-21, 2009.

16. Paolillo M and Schinelli S: Extracellular matrix alterations in metastatic processes. Int J Mol Sci 20: 4947, 2019.

17. Castro-Castro A, Marchesin V, Monteiro P, Lodillinsky C, Rossé C and Chavrier P: Cellular and molecular mechanisms of MT1-MMP-dependent cancer cell invasion. Annu Rev Cell Dev Biol 32: 555-576, 2016.

18. Shay G, Lynch CC and Fingleton B: Moving targets: Emerging roles for MMPs in cancer progression and metastasis. Matrix Biol 44-46: 200-206, 2015 .

19. Gonzalez-Avila G, Sommer B, Mendoza-Posada DA, Ramos C Garcia-Hernandez AA and Falfan-Valencia R: Matrix metalloproteinases participation in the metastatic process and their diagnostic and therapeutic applications in cancer. Crit Rev Oncol Hematol 137: 57-83, 2019.

20. Yousef EM, Tahir MR, St-Pierre Y and Gaboury LA: MMP-9 expression varies according to molecular subtypes of breast cancer. BMC Cancer 14: 609, 2014.

21. Stuelten CH, DaCosta Byfield S, Arany PR, Karpova TS, Stetler-Stevenson WG and Roberts AB: Breast cancer cells induce stromal fibroblasts to express MMP-9 via secretion of TNF-alpha and TGF-beta. J Cell Sci 118: 2143-2153, 2005.

22. Sand JM, Larsen L, Hogaboam C, Martinez F, Han M, Larsen MR, Nawrocki A, Zheng Q, Karsdal MA, Leeming DJ: MMP mediated degradation of type IV collagen alpha 1 and alpha 3 chains reflects basement membrane remodeling in experimental and clinical fibrosis - validation of two novel biomarker assays. PLoS One 8: e84934, 2013.

23. Kessenbrock K, Plaks V and Werb Z: Matrix metalloproteinases: Regulators of the tumor microenvironment. Cell 141: 52-67, 2010

24. Owyong M, Chou J, van den Bijgaart RJ, Kong N, Efe G, Maynard C, Talmi-Frank D, Solomonov I, Koopman C, Hadler-Olsen E, et al: MMP9 modulates the metastatic cascade and immune landscape for breast cancer anti-metastatic therapy. Life Sci Alliance 2: e201800226, 2019.

25. Li HC, Cao DC, Liu Y, Hou YF, Wu J,Lu JS, Di GH, Liu G, Li FM, Ou ZL, et al: Prognostic value of matrix metalloproteinases (MMP-2 and MMP-9) in patients with lymph node-negative breast carcinoma. Breast Cancer Res Treat 88: 75-85, 2004

26. Vizoso FJ, González LO, Corte MD, Rodríguez JC, Vázquez J, Lamelas ML, Junquera S, Merino AM and García-Muñiz JL: Study of matrix metalloproteinases and their inhibitors in breast cancer. Br J Cancer 96: 903-911, 2007.

27. Darlix A, Lamy PJ, Lopez-Crapez E, Braccini AL, Firmin N Romieu G, Thézenas S and Jacot W: Serum NSE, MMP-9 and HER2 extracellular domain are associated with brain metastases in metastatic breast cancer patients: Predictive biomarkers for brain metastases? Int J Cancer 139: 2299-2311, 2016.

28. Ranogajec I, Jakić-Razumović J, Puzović V and Gabrilovac J: Prognostic value of matrix metalloproteinase-2 (MMP-2), matrix metalloproteinase-9 (MMP-9) and aminopeptidase N/CD13 in breast cancer patients. Med Oncol 29: 561-569, 2012.

29. Li H, Qiu Z, Li F and Wang C: The relationship between MMP-2 and MMP-9 expression levels with breast cancer incidence and prognosis. Oncol Lett 14: 5865-5870, 2017.

30. Dhar M, Lam JN, Walser T, Dubinett SM, Rettig MB and Di Carlo D: Functional profiling of circulating tumor cells with an integrated vortex capture and single-cell protease activity assay. Proc Natl Acad Sci USA 115: 9986-9991, 2018.

31. Cierna Z, Mego M, Janega P, Karaba M, Minarik G, Benca J, Sedlácková T, Cingelova S, Gronesova P, Manasova D, et al: Matrix metalloproteinase 1 and circulating tumor cells in early breast cancer. BMC Cancer 14: 472, 2014

32. Cardoso F, Kyriakides S, Ohno S, Penault-Llorca F, Poortmans P, Rubio IT, Zackrisson S and Senkus E; ESMO Guidelines Committee: Early breast cancer: ESMO Clinical Practice Guidelines for diagnosis, treatment and follow-up. Ann Oncol 30: 1674,2019
33. Allison KH, Brogi $\mathrm{E}$ and Ellis IO: WHO Classification of Tumours Editorial Board. Breast Tumours. 5th edition. IARC Press, Lyon, 2019.

34. van Nes JG, de Kruijf EM, Putter H, Faratian D, Munro A, Campbell F, Smit VT, Liefers GJ, Kuppen PJ, van de Velde CJ, et al: Co-expression of SNAIL and TWIST determines prognosis in estrogen receptor-positive early breast cancer patients. Breast Cancer Res Treat 133: 49-59, 2012.

35. Chovanec M, Cierna Z, Miskovska V, Machalekova K, Svetlovska D, Kalavska K, Rejlekova K, Spanik S, Kajo K, Babal P, et al: Prognostic role of programmed-death ligand 1 (PD-L1) expressing tumor infiltrating lymphocytes in testicular germ cell tumors. Oncotarget 8: 21794-21805, 2017.

36. Chovanec M, Cierna Z, Miskovska V, Machalekova K, Kalavska K, Rejlekova K, Svetlovska D, Macak D, Spanik S, Kajo K, et al: $\beta$-catenin is a marker of poor clinical characteristics and suppressed immune infiltration in testicular germ cell tumors. BMC Cancer 18: 1062, 2018

37. Mego M, Karaba M, Minarik G, Benca J, Sedlácková T, Tothova L, Vlkova B, Cierna Z, Janega P, Luha J, et al: Relationship between circulating tumor cells, blood coagulation, and urokinase-plasminogen-activator system in early breast cancer patients. Breast J 21: 155-160, 2015.

38. Mego M, Karaba M, Minarik G, Benca J, Silvia J, Sedlackova T, Manasova D, Kalavska K, Pindak D, Cristofanilli M, et al: Circulating tumor cells with epithelial-to-mesenchymal transition phenotypes associated with inferior outcomes in primary breast cancer. Anticancer Res 39: 1829-1837, 2019.

39. Mego M, Mani SA, Lee BN, Li C, Evans KW, Cohen EN, Gao H, Jackson SA, Giordano A, Hortobagyi GN, et al: Expression of epithelial-mesenchymal transition-inducing transcription factors in primary breast cancer: The effect of neoadjuvant therapy. Int J Cancer 130: 808-816, 2012.

40. Yadav L, Puri N, Rastogi V, Satpute P, Ahmad R and Kaur G: Matrix metalloproteinases and cancer - roles in threat and therapy. Asian Pac J Cancer Prev 15: 1085-1091, 2014.

41. Westermarck J and Kähäri VM: Regulation of matrix metalloproteinase expression in tumor invasion. FASEB J 13: 781-792, 1999.

42. Alaseem A, Alhazzani K, Dondapati P, Alobid S, Bishayee A and Rathinavelu A: Matrix metalloproteinases: A challenging paradigm of cancer management. Semin Cancer Biol 56: 100-115, 2019.

43. González LO, Pidal I, Junquera S, Corte MD, Vázquez J, Rodríguez JC, Lamelas ML, Merino AM, García-Muñiz JL and Vizoso FJ: Overexpression of matrix metalloproteinases and their inhibitors in mononuclear inflammatory cells in breast cancer correlates with metastasis-relapse. Br J Cancer 97: 957-963, 2007.

44. Radisky ES, Raeeszadeh-Sarmazdeh M and Radisky DC: Therapeutic Potential of Matrix Metalloproteinase Inhibition in Breast Cancer. J Cell Biochem 118: 3531-3548, 2017.

45. Song J, Su H, Zhou YY and Guo LL: Prognostic value of matrix metalloproteinase 9 expression in breast cancer patients: A meta-analysis. Asian Pac J Cancer Prev 14: 1615-1621, 2013.

46. Ren F, Tang R, Zhang X, Madushi WM, Luo D, Dang Y, Li Z, Wei K and Chen G: Overexpression of MMP family members functions as prognostic biomarker for breast cancer patients: A systematic review and meta-analysis. PLoS One 10: e0135544, 2015.

47. Pellikainen JM, Ropponen KM, Kataja VV, Kellokoski JK, Eskelinen MJ and Kosma VM: Expression of matrix metalloproteinase (MMP)-2 and MMP-9 in breast cancer with a special reference to activator protein-2, HER2, and prognosis. Clin Cancer Res 10: 7621-7628, 2004.

48. González LO, Corte MD, Junquera S, González-Fernández R, del Casar JM, García C, Andicoechea A, Vázquez J, Pérez-Fernández R and Vizoso FJ: Expression and prognostic significance of metalloproteases and their inhibitors in luminal A and basal-like phenotypes of breast carcinoma. Hum Pathol 40: 1224-1233, 2009

49. Zhao S, Ma W, Zhang M, Tang D, Shi Q, Xu S, Zhang X, Liu Y, Song Y, Liu L, et al: High expression of CD147 and MMP-9 is correlated with poor prognosis of triple-negative breast cancer (TNBC) patients. Med Oncol 30: 335, 2013

50. Yang J, Min KW, Kim DH, Son BK, Moon KM, Wi YC, Bang SS, Oh YH, Do SI, Chae SW, et al: High TNFRSF12A level associated with MMP-9 overexpression is linked to poor prognosis in breast cancer: Gene set enrichment analysis and validation in large-scale cohorts. PLoS One 13: e0202113, 2018. 
51. Radisky ES and Radisky DC: Matrix metalloproteinase-induced epithelial-mesenchymal transition in breast cancer. J Mammary Gland Biol Neoplasia 15: 201-212, 2010.

52. Foroni C, Broggini M, Generali D and Damia G: Epithelialmesenchymal transition and breast cancer: Role, molecular mechanisms and clinical impact. Cancer Treat Rev 38: 689-697, 2012.

53. Li W, Li S, Deng L, Yang S, Li M, Long S, Chen S, Lin F and Xiao L: Decreased MT1-MMP in gastric cancer suppressed cell migration and invasion via regulating MMPs and EMT. Tumour Biol 36: 6883-6889, 2015.

54. Zhong Y, Lu YT, Sun Y, Shi ZH, Li NG, Tang YP and Duan JA: Recent opportunities in matrix metalloproteinase inhibitor drug design for cancer. Expert Opin Drug Discov 13: 75-87, 2018.

55. Arkadash V, Yosef G, Shirian J, Cohen I, Horev Y, Grossman M, Sagi I, Radisky ES, Shifman JM and Papo N: Development of high affinity and high specificity inhibitors of matrix metalloproteinase 14 through computational design and directed evolution. J Biol Chem 292: 3481-3495, 2017.

56. Winer A, Adams S and Mignatti P: Matrix metalloproteinase inhibitors in cancer therapy: Turning past failures intofuture successes. Mol Cancer Ther 17: 1147-1155, 2018.
57. Pozzi A, LeVine WF and Gardner HA: Low plasma levels of matrix metalloproteinase 9 permit increased tumor angiogenesis. Oncogene 21: 272-281, 2002.

58. Montel V, Kleeman J, Agarwal D, Spinella D, Kawai K and Tarin D: Altered metastatic behavior of human breast cancer cells after experimental manipulation of matrix metalloproteinase 8 gene expression. Cancer Res 64: 1687-1694, 2004.

59. Decock J, Hendrickx W, Thirkettle S, Gutiérrez-Fernández A, Robinson SD and Edwards DR: Pleiotropic functions of the tumor- and metastasis-suppressing matrix metalloproteinase- 8 in mammary cancer in MMTV-PyMT transgenic mice. Breast Cancer Res 17: 38, 2015.

60. Juurikka K, Butler GS, Salo T, Nyberg P and Åström P: The role of MMP8 in cancer: A systematic review. Int J Mol Sci 20: 4506, 2019. International (CC BY-NC-ND 4.0) License. 